\section{The physician-scientist: An essential - and fragile - link in the medical research chain}

\author{
Leon E. Rosenberg \\ Department of Molecular Biology, Princeton University, Princeton, New Jersey 08544, USA. \\ Phone: (609) 258-6224; Fax: (609) 258-2340; E-mail: lrosenberg@molbio.princeton.edu.
}

\section{Perspective}

Editor's note: This Perspective is based on the second annual Shannon Lecture at the National Institutes of Health, delivered by Dr. Rosenberg in October 1998. A shorter version was published previously ("Physician-Scientists - Endangered and Essential," Science. 283:331-332; 1999).
It was a singular honor for me to give the second annual James A. Shannon Lecture at the National Institutes of Health last October. Indeed, I would not have been there at all without Shannon. That is not because I knew him personally, but rather because of the NIH that he more than anyone else - created between 1949 and 1968. Shannon's intelligence, vision, decisiveness, singlemindedness, and political acumen, first as Associate Director for Research of the National Heart Institute and then as Director of NIH, produced a powerful magnet that attracted me to Bethesda in 1959. Forty years later, I had the opportunity to reflect on why preparing one's self for a career in research, as epitomized by coming to NIH, was so clearly the thing for recent medical school graduates to do then and, just as clearly and paradoxically, is not the thing to do today. What follows are my reflections I offered in the Shannon lecture.

I came to Bethesda as a clinical associate in the Metabolism Service of the National Cancer Institute. Things began badly: I didn't get along with the person to whom I was assigned, and I refused to work on the project that he proposed. I was rescued by Nathaniel Berlin, chief of the Metabolism Service, who gently reminded me that I was a novice in research, urged me to remind myself of that before jumping to conclusions, and then generously allowed me the time and freedom to find a more suitable research setting. I wandered about for the better part of a year until I became responsible for the care of an 8-year-old boy named Steven (Figure 1). He had been admitted to the Clinical Center with a previously undescribed familial disorder characterized by progressive skeletal muscle wasting and a renal tubular defect selective for amino acids. He died two years later, just as two of his brothers had, leaving behind a host of unanswered questions about the cause of his disorder and the relationship between its pathophysiologic effects on muscle and kidney (1). Meanwhile, I read everything I could about medical genetics and amino acid metabolism, and developed a hypothesis about what was going on. But I needed a place to work and someone to teach me. These I found in the laboratory of Stanton Segal in the National Institute of Arthritis and Metabolic Diseases. Segal, an accomplished physician-scientist, was an ideal mentor for me - interested in understanding the biochemical basis of inherited metabolic diseases, inventive about designing laboratory experiments, nurturing, and tireless. I will never forget the thrill that I felt the first day I conceived, planned, carried out, and interpreted an experiment that measured the uptake of radioisotopi- cally-labeled amino acids by slices of rat renal cortex. Although the findings were hardly earth shaking in retrospect, the sense of well being and exuberance they engendered were so intense that I knew I must direct my career toward medical research.

And so I did, and have done ever since. After six years I moved from NIH to the Yale School of Medicine. During the next 26 years I moved freely among the departments of Internal Medicine, Pediatrics, and Human Genetics, and as freely among the core functions of a university research, teaching, patient care, public service, and administration. But there was one constant: my research laboratory. Exploiting the rapidly increasing knowledge of genetics and the robust technologies emanating from biochemistry, cell, and molecular biology - but always starting at the bedside of a sick child - my colleagues and I sought to understand a series of inherited metabolic diseases and to use this understanding toward improved means of diagnosis, prevention, and treatment (2). Some referred to me as a basic scientist because I worked in the laboratory, asked about mechanisms of disease, and employed reductionist approaches. But I always thought of myself as a clinical investigator, because the inspiration for the work always came from caring for sick children and because much of the work was carried out with intact patients and their families. I didn't much care how our research was classified, as long as it was of the highest quality possible. Yet others did care, and as you will hear in a few minutes, still do, although I've never been sure why.

And then, in 1991, I left Yale and became President of the Pharmaceutical Research Institute of Bristol-Myers Squibb. I will most remember those seven exciting and turbulent years for the remarkable multi-disciplinary teamwork that is industry's great strength and for the pharmaceuticals that I "put my fingerprints on" including Taxol, Pravachol, Zerit, Maxipime, and Avapro.

What I did not know when I moved to Bristol-Myers Squibb was that Shannon had made the same transition 45 years earlier. After 15 remarkably productive years at New York University School of Medicine during which he carried out fundamental research in renal physiology and led patient-oriented research on the clinical evaluation of new anti-malarial drugs, Shannon surprised everyone by becoming the director of the E.R. Squibb Institute for Medical Research, the precursor of today's Pharmaceutical Research Institute. He stayed in industry only three years before moving to the National Heart Institute, but that was long enough to set the Squibb Institute's 


\section{Figure 1}

Stephen, the proband who kindled my interest in genetic disorders Reprinted, with permission from Excerpta Medica Inc. (Rowley, P.T., Mueller, P.S., Watkin, D.M., and Rosenberg, L.E. 1961. Familial growth retardation, renal aminoaciduria, and cor pulmonale. I. Description of a new syndrome with case reports. Am. J. Med. 31:187-204.)

research direction, to oversee the development of streptomycin, to initiate the screening program that led to the development of isoniazid, and to establish work on hypotensive and anti-inflammatory corticosteroids.

Shannon, then, came to NIH with broad experience in academia and industry. He came, too, with profound faith in the power of science to transform medicine into a far more effective instrument for improving the human condition, with the conviction that only the federal government had pockets deep enough to provide the resources necessary to realize the scientific potential of the country and with the belief that his aspirations could be fulfilled only by a talented research work force led by Ph.D.s and M.D.s. In 13 years Shannon transformed the country's medical research edifice - not alone of course, but with the invaluable help of colleagues at NIH, a symbiotic partnership with Senator Lister Hill and Representative John Fogarty, and the tireless efforts of the first real citizen/advocate for medical research, Mary Lasker (3).

The accomplishments of the Shannon era, so prodigious that they cannot be overstated, rocketed basic research in the life sciences into a new orbit. Clinical research, too, was propelled as insights from basic science were applied to an understanding of diseases and, as important, as observations made at the bedside raised new questions about the biology of mankind and other organisms. The proverbial bridge between bedside and bench was built and buttressed. This bridge, and its attendant partnerships between M.D.s and Ph.D.s, set the American medical research enterprise apart from those in Japan and Europe. Some would say it was our greatest strength, and this, too, is worth remembering.

Today, the medical research enterprise of the United States is the unquestioned world leader. This complex enterprise consists of a unique, and increasingly interactive, collaboration among government, academia, industry, independent institutes, foundations, not for profit organizations, voluntary health agencies, and public advocacy groups. It is preeminent in science - fundamental and applied, basic and clinical, laboratory-based and patient oriented. It has expanded its horizons to concern itself with populations as well as individuals, with health as well as disease, with ethical dilemmas as well as medical ones.

As the next millennium nears, this enterprise seems poised to make ever greater contributions to the health and well being of people everywhere and, hence, to both the national and international interest. The public senses this excitement and is being heard. Research!America's national grassroots polls reveal that the public wants medical research to have a higher priority and believes that a larger fraction of the nation's health expenditures should be devoted to research. Disease-specific advocates petition

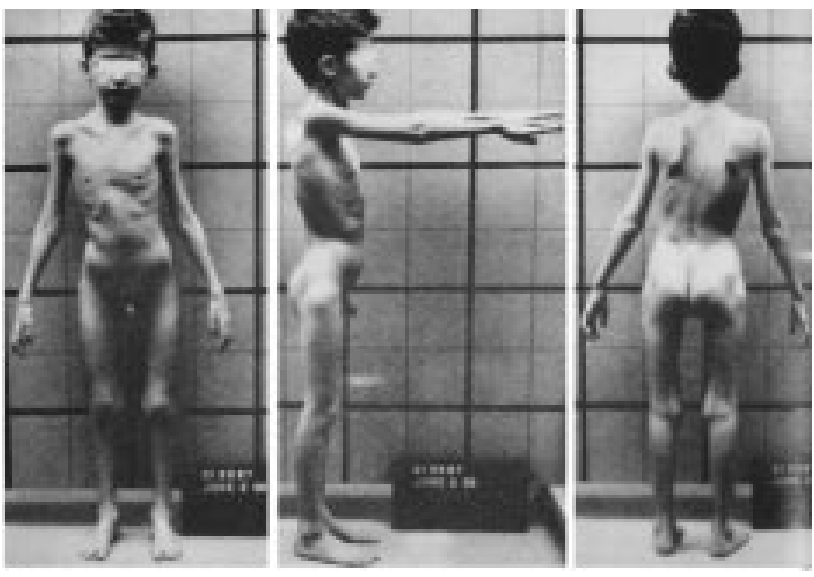

Congress for a greater fraction of the federal research "pie"; in turn, Congress asks NIH, directly and through the Institute of Medicine, how it establishes its priorities, and how it should hear from its many public constituencies (4). And, just last year, Congress approved a fiscal year 1999 budget for NIH of 15.6 billion dollars, 2 billion more than in 1998, and the largest increase ever.

All of this should make me shout "right on!" or "yes!" I assure you, it does. But I also find myself asking if we are doing enough to sustain and strengthen the treasure that is the American medical research enterprise. Today, I must tell you about a defect in the structure of the country's medical research edifice, which must be repaired soon and well, lest it threaten the entire construct. I speak of the progressive, dangerous decline in the number of physician-scientists. I will use the designation "physician-scientist" for the entire species of M.D.s who devote all or a majority of their professional effort to seeking new knowledge about health and disease using established scientific principles. I intend the designation to be inclusive; that is, it covers basic, disease-oriented, patient-oriented, population-oriented, and prevention-oriented investigation.

This decline is not a new problem. Former NIH director, James Wyngaarden, first called attention to it 20 years ago in his paper entitled, "The Clinical Investigator as an Endangered Species” (5). In 1984 Gordon Gill wrote a paper entitled, "The End of the Physician-Scientist?" (6). I read each of these thoughtful and well-argued pieces. After all, I was one of the members of the presumably threatened species. But I paid no attention. Twenty years ago I was having such a marvelous time running my NIHsupported laboratory that I simply couldn't believe that the danger was real. In 1984 I had just accepted the deanship at Yale and was consumed with its institutional demands. In retrospect, I guess I just couldn't look in the mirror and see a dinosaur. Denial must be mediated by a most potent neurotransmitter.

Subsequently, the problem has been called to our attention repeatedly but with an important shift of emphasis away from those doing the science, and toward the kind of science being done - namely, that directly oriented toward patients (7). Since 1991, two panels, one sponsored by the Institute of Medicine and chaired by William Kelley (8), and the other appointed by Harold 
Varmus and chaired by David Nathan (and on which I served; ref. 9), have wrestled with the flammable issue of how to define the term "clinical research," have come to different estimates of how much is being funded by NIH, and have recommended ways to deal with serious threats to clinical research and clinical researchers. Finally, in last year's Shannon Lecture, Joe Goldstein talked about the bewitched, bothered, bewildered, and beloved clinical investigator (10).

Given all this activity, as well as several recent commentaries (11-13), why do I choose to address this issue yet again? First, because the entire species of physicianscientists is at risk - not only those doing patient-oriented research. Think of it as conservation biologists would: we've been so focused recently on the spotted owl (that is, physicians who do patient-oriented research) that we haven't noticed that all the owls are at risk (that is, all physician-scientists). Second, because endangering physician-scientists endangers everyone concerned with medical research. Third, because the actions taken to date can't solve the problem. And fourth, because this threat can be averted only by bold, concerted action on the part of all of the participants in the country's medical research enterprise.

I intend to address four questions regarding the proposition that physician-scientists are an endangered species in serious jeopardy of vanishing. First, what is the evidence? Second, does it matter? Third, why has it happened? And fourth, what can be done?

First, the evidence. It comes largely from detailed analysis of trends in applications for NIH project grants and traineeships. Being supported by NIH is not, of course, the only way to establish or sustain a research career, but it is a bellwether because of the NIH's size, national scope, and reputation.

In 1970, M.D.s and M.D./Ph.D.s submitted about 3,000 research project grant applications and received 1,200 awards (Figure 2). In that year Ph.D.s submitted about 5,800 applications and were awarded about 2000 grants. From then to the present, Ph.D.s have been applying in far larger numbers than have M.D.s and have received correspondingly more awards. In the most recent year for which we have data, 1997, M.D.s were awarded about 2,100 grants as compared to about 5,200 for Ph.D.s. When these data are expressed as percentages, they show that in 1967, 43 percent of the awarded research project grants went to M.D.s and M.D./Ph.D.s, compared with 53 percent for Ph.D.s (Figure 3). The fraction of awards to M.D.s fell progressively during the next 20 years to a low of 25 percent in 1987 . There has been little change in these fractions during the past decade. Throughout this nearly 30-year interval, the success rates for M.D.s and Ph.D.s have been virtually identical with one another; that is, M.D.s have fared as well as Ph.D.s have at the hands of NIH study sections and advisory councils when they compete. But physician-scientists have become a progressively smaller minority of those seeking and obtaining NIH project support.

As disturbing as this evidence of declining interest is, it does not account for the alarm I feel. To me, the most powerful evidence that physician-scientists are progressively endangered comes not from looking at established investigators but rather at recent trends in the populations of new investigators and trainees. The actual number of first time M.D. applicants for NIH research project grants has plummeted in the past few years from 838 in 1994, to 687 in 1995, to 589 in 1996, to 575 in 1997 - a 31 percent fall (Figure 4). Since first-time applicants had about a 22 percent success rate in 1997, this means that in 1997 only 126 M.D.s in the entire country were successful the first time they sought to be P.I.s on an NIH research project grant. If this progression were to continue linearly, there would be no first-time M.D. applicants by 2003. Furthermore, the drop in first-time M.D. applicants was not made up by M.D./Ph.D.s; there have been fewer than 200 first-time applicants from this group annually and their number shows no significant trend.

These data indicate that progressively fewer young M.D.s are interested in (or perhaps prepared for) careers as independent NIH-supported investigators. This unhappy conclusion is supported by examining data on trainees. In 1980 the total number of M.D. postdoctoral trainees supported by NIH through individual fellowships and training grants was 2,241; this number rose during the 80's and then plateaued; but since 1992, the actual number has fallen steadily. In 1992 the number was 2,613 ; in $1997,1,261$ - a 51 percent decrease. When the number of M.D.s and Ph.D.s is expressed as a fraction of all trainees, the course of events during the past decade is starkly graphic (Figure 5). If this trend is not changed, there will be no M.D.s in this pool by 2006 . Recent data from the Howard Hughes Medical Institute are just as discouraging. In the past two years, the number of M.D.s and M.D./Ph.D.s applying for the prestigious HHMI postdoctoral fellowships has fallen from 276 in 1996 to 152 in 1998 - a 45 percent drop.

Finally, we should note the results of the annual questionnaire of the Association of American Medical Colleges completed by all graduating medical students in the country (Figure 6). In 1989, 14 percent expressed a strong interest in research as a career; that fraction fell in almost each successive year, reaching 10 percent in 1996. The human pipeline of physician-scientists is emptying at the worst possible spot - the young end.

Now I want to turn to the second question I posed: Does it matter if physician-scientists constitute a smaller and smaller segment of the community of medical researchers, and perhaps ultimately even disappear? After all, some say, there are plenty of well-trained Ph.D.s and many of them are now doing clinical research. If

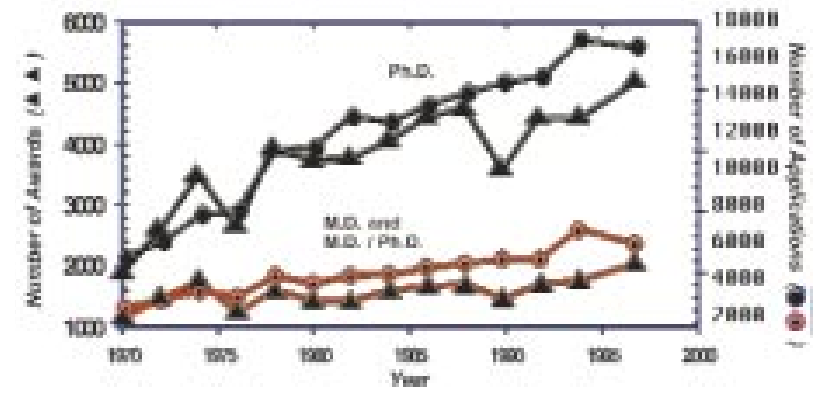

Figure 2

$\mathrm{NIH}$ research project grants. 


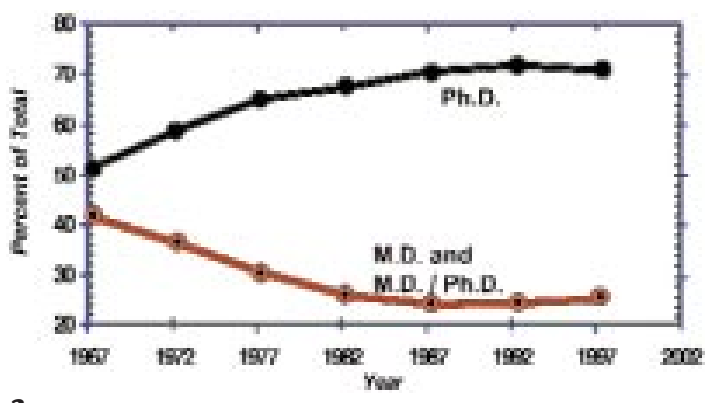

Figure 3

$\mathrm{NIH}$ research project grants.

M.D.s are unwilling to take the risks of a very competitive research career, so be it. My reply is as follows. It may be true that a medical education does not adequately prepare one to answer scientific questions, but it is the ideal setting in which to ask them. Let me illustrate this by imagining our medical research system devoid of physician-scientists. Who will ask why our ability to cure Hodgkin's disease is so much better than that for most other cancers if there are no scientifically-trained oncologists who have had to discuss treatment options and prognosis with a teenage girl newly diagnosed with Hodgkin's disease? Who will ask how lithium prevents both manic and depressive episodes if there are no research psychiatrists, who have helped rescue a suicidal patient with manic depression? Who will train the physician-scientists that the biopharmaceutical industry employs to design, direct, and interpret their clinical trials if there are no physician-scientists in academia doing patient-oriented research? When we have mapped and sequenced the entire human genome, who is going to make the long-sought connections between these genes and sick people if there are no physicians engaged in answering tomorrow's questions about the role that genes play in virtually all medical problems? It is the diversity in backgrounds of M.D. and Ph.D. scientists that will make reading this "book of man" so exciting. We must not fool ourselves. In the absence of physicianscientists, the bridge between bench and bedside will weaken - perhaps even collapse. This would not only impair the ability for a new question inspired by a sick person to be taken to the laboratory; it would impede the flow of disease-relevant information from Ph.D.s to their clinical colleagues. Physicians-scientists are a critical link in the medical research chain. They can communicate and collaborate with Ph.D. scientists on one side and with health care providers on the other as no other group can. They can make the case for the clinical relevance of basic research to voluntary health agencies, advocates, and legislators because they are living it. We must not forget that the public equates health with medicine and medicine with physicians. Will public support for NIH and other "health" research agencies be as strong without physician-scientists, and the many links they forge to the rest of the enterprise? I think not.

My third question: Why is the number of physician-scientists declining at the very time that their scientific opportunities are greater than ever before? Why, except for a brief interval between 1950 and 1965, have M.D.s who do science not been reproducing themselves in sufficient numbers? Why has my generation of physicianscientists failed to pass the torch to the next generation? Not because we have lacked our scientific heroes. Since World War II, half of the 122 winners of the Nobel Prize in Physiology or Medicine have been M.D.s. The Lasker Awards make the same case. Of the 112 winners of the Lasker Award for Basic Medical Research, 53 have been M.D.s. Clearly, heroes are not enough.

The stated reasons physician-scientists are endangered are many and varied. We don't know their relative importance, yet they bear repeating so that they will be debated, analyzed, and addressed. First, there has been a strong message from the general public about what society needs from physicians, that is, what a physician's responsibilities should be. For 30 years, medical educators, medical students, and physicians in training have been hearing that physicians have an obligation: to think more about primary care and less about specialization; to devote more of their energies to the underserved and underrepresented; to care more about the public interest and less about their self interest. There can be no quarrel with these messages, but they have not been balanced by other equally important ones: that improving health requires more research; that, because of their unique perspective, physicians must be key participants in medical research. Second, there is a set of economic disincentives that have tended to push the youngest members of the medical profession away from research. These disincentives include the growing debt burden for medical school graduates, now averaging 80 thousand dollars; the modest stipends paid to postdoctoral trainees by NIH and other sponsors; and, until recently, the large disparity between incomes of practicing medical specialists and those doing research. Third, there has been a progressive increase in the number of years of postdoctoral training required for physicians undertaking careers in research, often stretching to 10 or more, and a widely perceived decrease in the adequacy of research training programs, particularly in clinical departments. Such programs, it is argued, have not kept pace with the rate and complexity of scientific progress. To earn the name "physician," M.D.s must devote some postgraduate years to caring for the sick. To earn the designation "scientist," M.D.s must learn to plan, conduct, and interpret experiments with the same rigor their Ph.D. colleagues do, whether they are doing patient-oriented research, clinical epidemiology, or basic laboratory investigation. Fourth, the increas-

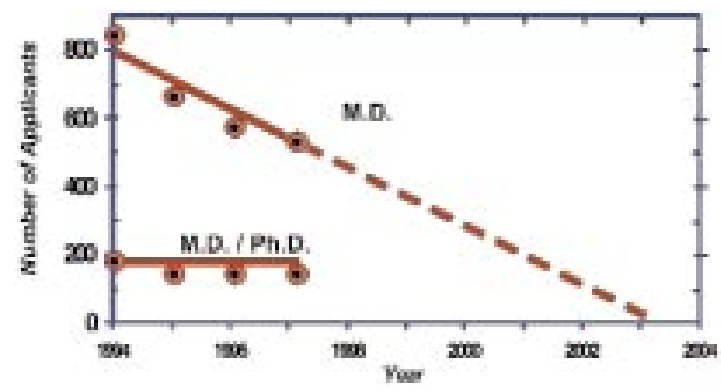

Figure 4

First-time applicants for $\mathrm{NIH}$ research project grants. 


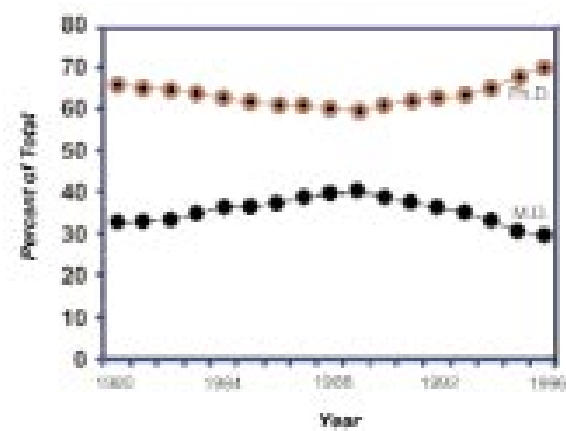

Figure 5

$\mathrm{NIH}$ postdoctoral research training positions.

ing instability of NIH-supported research careers: falling success rates resulting in more time being spent writing and rewriting grant applications; poorly constituted study sections biased against patient-oriented research; increasing competition from the growing pool of Ph.D. applicants; the short "half-life" of funding for new and established investigators; the dearth of alternate sources of research funding, both private and public. Fifth, the explosive growth of managed care. This has imposed financial constraints on all academic health centers. To make up for this revenue shortfall, leaders of clinical departments have demanded that their faculties see more patients. More time for patient care, of course, means less time for research. The relative importance of these factors must surely vary. Collectively, they have resulted in a climatic change in academic health centers that is toxic to spawning young investigators. Instead of hearing about the remarkable scientific opportunities that lie ahead, medical students hear about how difficult it is to get research funds. Instead of being told what a wonderful time successful investigators have, students are told how little time investigators have for research. Instead of witnessing their mentors practice an academic life style devoted to teaching and discovering, students witness faculty harried and harassed by the heavy institutional pressure of the financial "bottom line." Should it surprise us that students are not flocking to emulate their physician-scientist teachers? It's difficult enough to follow a role model. It's harder still when the "role" appears less and less satisfying, and when those who should be role models become anti-role models instead.

Finally, what's to be done and who is to do it? Most important, we must reach consensus on several key matters: that the entire class of physician-scientists is at risk; that this will have a deleterious effect on all kinds of basic and clinical research - laboratory, patient-oriented, epidemiologic, outcomes; and that a comprehensive, national effort will be required to solve the problem. I suggest we take a page from the book of experiences of conservation biologists and ecologists who have, for some years, been dealing with threatened or endangered species in the wild. Ecologists talk about quantification, surveillance, habitat fragmentation, predators, breeding grounds, and protection. It is not difficult to find an apt analogy for each of these words when addressing the problem of the endangered physician-scientist, so I'd like to repeat them: quantification, surveillance, habitat frag- mentation, predators, breeding grounds, and protection.

Because this problem affects all participants in our national enterprise, its solution, too, demands their involvement. Whereas I endorse the recommendations of the Nathan Panel, and am pleased that several of them have already been acted on, they will not, in my opinion, change the dangerous course we are on, because these recommendations are directed largely to NIH, and NIH cannot meet this challenge alone. Nor can the IOM or the AAMC or the AMA or the country's medical schools and academic health centers alone. I believe we need a collaborative national effort, and I believe this can be fashioned best by a legislative solution along the lines of a bill originally proposed by Senators Mark Hatfield and Ted Kennedy in 1996. The bill I have in mind would mandate appointment of a broad-based national panel composed of leaders from NIH, academia, industry, foundations, and public life, and charge the panel to develop their initial recommendations in fewer than 12 months. This group should reflect on all of the factors that have led to the endangerment of physician-scientists - motivational, structural, and economic - and be a forceful agent for rapid change.

These are some of the things I hope such a panel would propose in initiating a program for physician-scientist revitalization and repopulation:

First, and foremost, reestablish a supportive environment in academia. This is, after all, the breeding ground for physician-scientists and the very habitat that has undergone fragmentation. Undergraduates with an interest in attending medical school should be advised that they need a strong background in science to succeed, and medical school admissions committees should recruit more students with demonstrable commitment to, and aptitude for, research. Would-be medical students are both perceptive and impressionable. We must pay attention to the signals we send them. Thereafter, the responsibility rests with deans, chairs, and senior faculty. Medical students should be encouraged by them to seek intensive research experiences early, and should be rewarded for so doing. Faculty doing research should be protected by them regardless of the impact on the "bottom line." Perhaps refocusing on the "top line" - namely, acquiring and disseminating new knowledge - is in order. Hospital CEOs should be reminded by them that tomorrow's medical care depends on today's medical research.

Second, create and/or expand attractive training programs for medical students, M.D./Ph.D. students, post-

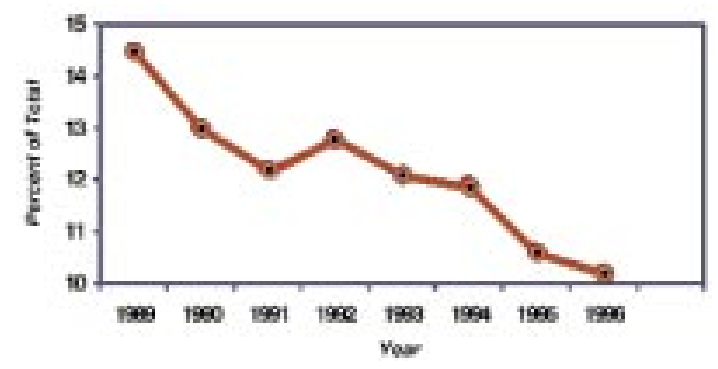

Figure 6

Graduating medical students with strong research career intentions. 
doctoral fellows, and junior faculty. NIH's role here is central, but HHMI and others must participate as well. The newly established K23 and K24 awards for young and mid-career faculty are a small step in the right direction. The MSTP program should be expanded and modified to permit sequential study toward the M.D. and Ph.D. degrees and to include students with interests in such fields as biostatistics, computer science, epidemiology, and population health. The programs enabling medical students to take a year out of the regular medical school curriculum to do research at NIH or in their own institutions should be expanded and encouraged. Rigorous, tailored postdoctoral research experiences must be designed and implemented in order that physician-scientists regain their confidence and belief in a research career. To recruit more of the best and brightest, these programs must offer financial incentives commensurate with the national need. Attractive stipends, loan repayment programs, and a higher likelihood of success must be built in. Yes, I can hear you say, this will cost money. Of course it will, but I can think of no better way to invest some of the two billion dollars in new money that NIH has been authorized to receive in 1999.

Third, establish a National Center for Clinical Research linking the Clinical Center at NIH with the general clinical research centers and clinical trials programs in academia. Such a network would foster collaborative educational efforts, training programs, and research projects aimed at strengthening patient-oriented research. It would stimulate traffic of people and ideas between Bethesda and the medical schools across the nation. It would heighten the visibility of clinical research.

Fourth, increase participation of foundations, biopharmaceutical companies, health insurance firms, and the managed care industry. Each of these participants should seek their own ways to partner with NIH and academia. Foundations should expand the range of training opportunities and career awards, following the lead shown by the Burroughs Wellcome Fund. Insurance companies and the managed care industry should support population studies and outcomes research, as well as the young people being educated to carry out these and related studies. Biopharmaceutical companies are ideally positioned to provide mentors, training sites, research projects, and funds. I would like to applaud the Pfizer Corporation for their recent 1.5 million dollar contribution to the NIH's National Foundation for Biomedical Research to support medical students who spend a year at NIH doing research. This is the kind of example that others should follow.

Fifth, develop and maintain a national database of physician-scientists. This database should track the number of medical students and M.D. graduates entering research training, the number of M.D.s supported by NIH and other research sponsors, the number of established investigators in academia, NIH, industry, and independent institutes, the number of M.D.s leaving research careers at all levels, and the number of physician-scientists needed by the various sectors. Fortuitously, the National Research Council of the National Academy of Sciences has just issued an important report on trends in careers of life-science Ph.D.s (14). This would be the ideal time to conduct a similar review of physician-scientists.

To conclude, the kind of broad program just outlined is necessary if we are to reverse the major threat to the nation's medical research ecosystem posed by the endangered physician-scientist. It is unthinkable that the symbolic graveyard of lost species, which ecologists use to dramatize their concerns, could one day contain a stone with the words "physician-scientist" on it. Because we have all waited too long, recovery will take many years and will be costly. If we wait any longer, we will not only increase the cost but, more important, will increase the probability that we will be too late to prevent virtual or real extinction. We must act now to change the climate in which today's physician-scientists work, because their words and actions will influence the choices their students make. We must act now to create a national environment conducive to creating a new generation of physician-scientists - rigorous in their training, confident in their ability to compete and succeed, and, above all, imbued with the belief that their efforts are essential if we are to improve the lives of people everywhere young and old, woman and man, sick and well.

\section{Acknowledgments}

Belinda Seto at NIH and Andrew Quon at AAMC were extraordinarily helpful in providing the data shown in Figure 1. Tom Kennedy, John Sherman, and Steve Highcock helped educate me about James Shannon. Bruce Alberts, Barbara Culliton, Alan Schechter, Dan Rubenstein, Harold Shapiro, Sam Silverstein, and Shirley Tilghman offered wise comments about the manuscript. Patricia Fox provided expert secretarial support. Finally, I am indebted to the NIH Alumni Association for the invitation to be the second James Shannon lecturer, and to Alan Schechter for being a true comrade regarding the many issues confronting physician-scientists and clinical research.

1. Rosenberg, L.E., Mueller, P.S., and Watkin, D.M. 1961. A new syndrome: familial growth retardation, renal aminoaciduria, and cor pulmonale. II. Investigation of renal function, amino acid metabolism, and genetic transmission. Am. J. Med. 31:205-215.

2. Rosenberg, L.E. 1990. Treating genetic diseases: lessons from three children. Pediatric Res. 27 (Suppl.) 510-516.

3. Kennedy, T.J., Jr. 1994. An appreciation: James Augustine Shannon (1905-1994). Academ. Med. 69:653-655.

4. Scientific Opportunities and Public Needs. Improving Priority Setting and Public Input at the National Institutes of Health. National Aca. Press, Washington, DC, 1998. 120.

5. Wyngaarden, J.B. 1979. The clinical investigator as an endangered species. N. Engl. J. Med. 23:1254-1259.

6. Gill, G.N. 1984. The end of the physician-scientist? The American Scholar. 53:353-368.

7. Ahrens, E.H., Jr. 1992. The crisis in clinical research, overcoming institutional obstacles. Oxford University Press. New York, N.Y. 236.

8. Careers in clinical research, obstacles and opportunities. W.N. Kelley and M.A. Randolph, editors. National Aca. Press, Washington, DC, 1994. 332.

9. Nathan, D.G. 1998. Clinical research, perceptions, reality, and proposed solutions. JAMA. 16:1427-1431.

10. Goldstein, J.L., and Brown, M.S. 1997. The clinical investigator: bewitched, bothered, and bewildered-but still beloved. J. Clin. Invest. 99:2803-2812.

11. Williams, G.H., Wara, D.W. and Carbone, P. 1997. Funding for patientoriented research. JAMA. 3:227-231.

12. Thompson, J.N., and Moskowitz, J. 1997. Preventing the extinction of the clinical research ecosystem. JAMA. 3:241-245.

13. Schechter, A.N. 1998. The crisis in clinical research. JAMA. 16:1440-1442.

14. Trends in the Early Careers of Life Scientists. National Aca. Press, Washington, DC, 1998. 178 . 